ARTICLE

\title{
Highly efficient ethylene production via electrocatalytic hydrogenation of acetylene under mild conditions
}

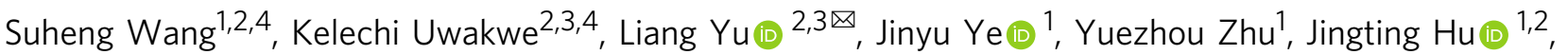
Ruixue Chen ${ }^{1,2}$, Zheng Zhang ${ }^{1,2}$, Zhiyou Zhou (1) ${ }^{1}$, Jianfeng Li (i) ${ }^{1}$, Zhaoxiong Xie ${ }^{1}$ \& Dehui Deng (1) ${ }^{1,2,3 凶}$

Renewable energy-based electrocatalytic hydrogenation of acetylene to ethylene (E-HAE) under mild conditions is an attractive substitution to the conventional energy-intensive industrial process, but is challenging due to its low Faradaic efficiency caused by competitive hydrogen evolution reaction. Herein, we report a highly efficient and selective E-HAE process at room temperature and ambient pressure over the $\mathrm{Cu}$ catalyst. A high Faradaic efficiency of $83.2 \%$ for ethylene with a current density of $29 \mathrm{~mA} \mathrm{~cm}^{-2}$ is reached at $-0.6 \mathrm{~V}$ vs. the reversible hydrogen electrode. In-situ spectroscopic characterizations combined with firstprinciples calculations reveal that electron transfer from the Cu surface to adsorbed acetylene induces preferential adsorption and hydrogenation of the acetylene over hydrogen formation, thus enabling a highly selective E-HAE process through the electron-coupled proton transfer mechanism. This work presents a feasible route for high-efficiency ethylene production from E-HAE.

\footnotetext{
${ }^{1}$ State Key Laboratory for Physical Chemistry of Solid Surfaces, Collaborative Innovation Center of Chemistry for Energy Materials, College of Chemistry and Chemical Engineering, Xiamen University, Xiamen 361005, China. ${ }^{2}$ State Key Laboratory of Catalysis, Collaborative Innovation Center of Chemistry for Energy Materials, Dalian Institute of Chemical Physics, Chinese Academy of Sciences, Dalian 116023, China. ${ }^{3}$ University of Chinese Academy of Sciences, Beijing 100049, China. ${ }^{4}$ These authors contributed equally: Suheng Wang, Kelechi Uwakwe. ${ }^{凶}$ email: lyu@dicp.ac.cn; dhdeng@dicp.ac.cn
} 
ntegrated with technology of acetylene production from natural gas or coal, selective hydrogenation of acetylene to ethylene (HAE) has emerged as a promising non-oil route for producing ethylene, which is one of the most important building blocks in chemical synthesis ${ }^{1-3}$. Thermocatalytic HAE typically requires high temperatures above $200^{\circ} \mathrm{C}$ and high pressures of around $5 \mathrm{bar}^{4-8}$, and thus is highly energy demanding. Besides, large amount of $\mathrm{H}_{2}$ consumption makes the process even more costly. Moreover, the selectivity of ethylene is also hardly controllable owing to the undesired but facile excessive hydrogenation of acetylene to ethane under the harsh reaction conditions in the thermocatalytic $\mathrm{HAE}^{9-12}$. Therefore, it is of great significance to develop a more economical, energy-efficient, and highly selective route for the HAE process.

Herein, we report a highly efficient and selective electrocatalytic HAE (E-HAE) process at room temperature and ambient pressure over carbon-supported $\mathrm{Cu}$ microparticles (MPs). In contrast to the thermocatalytic path, this process is advantageous in being operatable under mild conditions and is environmentalfriendly in combination with electroreduction of water based on renewable electricity, in which hydrogen is in-situ generated for the reduction reaction so that extra supply of $\mathrm{H}_{2}$ can be avoided (Fig. 1), which emerges as an attractive route for semihydrogenation of alkynes ${ }^{13-15}$. By optimizing the $\mathrm{Cu}$ catalyst to expose more active facets, preferential adsorption and hydrogenation of acetylene is facilitated against hydrogen adsorption and evolution. In combination with adjusting the electrode potential to modulate the selectivity of the reduction products, excessive hydrogenation of acetylene to ethane is fully avoided at cathode potentials above $-0.6 \mathrm{~V}$ vs. reversible hydrogen electrode (RHE). By coating the carbon support with a microporous gas diffusion layer (GDL) to promote mass transfer, a high Faradaic efficiency of $83.2 \%$ for ethylene production $\left(\mathrm{FE}_{\mathrm{C}_{2} \mathrm{H}_{4}}\right)$ is achieved with an overall current density $(j)$ of $29 \mathrm{~mA} \mathrm{~cm}^{-2}$ at $-0.6 \mathrm{~V}$ vs.
RHE. The geometric current density for ethylene formation $\left(j_{\mathrm{C}_{2} \mathrm{H}_{4}}\right)$ reaches $26.7 \mathrm{~mA} \mathrm{~cm}^{-2}$ at $-0.7 \mathrm{~V}$ vs. RHE. By using continuous gas-flow method in the E-HAE process, the faradaic efficiency and the overall formation rate of ethylene are largely improved compared with those in closed reaction systems of previous reports ${ }^{16-21}$. In situ spectroscopic characterizations combined with density functional theory (DFT) calculations demonstrate that electron transfer from the $\mathrm{Cu}$ surface to adsorbed acetylene promotes the adsorption and hydrogenation of the acetylene, while suppressing the competitive hydrogen evolution reaction (HER) and facilitating ethylene desorption, thereby resulting in highly selective ethylene production. The electrochemical hydrogenation proceeds via the electron-coupled proton transfer pathways, which require higher activation energies for further hydrogenation steps than the desorption of the generated ethylene, so that the excessive hydrogenation to ethane is effectively inhibited. This process provides a green route for industrial production of $\mathrm{C}_{2} \mathrm{H}_{4}$ from $\mathrm{C}_{2} \mathrm{H}_{2}$ beyond the removal of $\mathrm{C}_{2} \mathrm{H}_{2}$ impurities in $\mathrm{C}_{2} \mathrm{H}_{4}{ }^{14,15}$.

\section{Results and discussion}

Structure and E-HAE performance of the $\mathrm{Cu}$ catalyst. The $\mathrm{Cu}$ MPs were prepared via a facile solvothermal route in ethylene glycol (EG) using $\mathrm{CuSO}_{4} \cdot 5 \mathrm{H}_{2} \mathrm{O}$ as precursors. The morphology of the $\mathrm{Cu}$ catalyst was characterized by scanning electron microscopy (SEM, Fig. 2a), high angle annular dark-field scanning transmission electron microscopy (HAADF-STEM) (Fig. 2a) and transmission electron microscopy (TEM) (Supplementary Fig. 1), which show that the $\mathrm{Cu}$ MPs are uniformly distributed with diameters of around $1 \mu \mathrm{m}$. Powder X-ray diffraction (XRD) characterizations show that the $\mathrm{Cu}$ MPs with face-centered cubic (fcc) structure mainly expose (111), (100), and (110) facets, but possessing more (100) and (110) facets than the

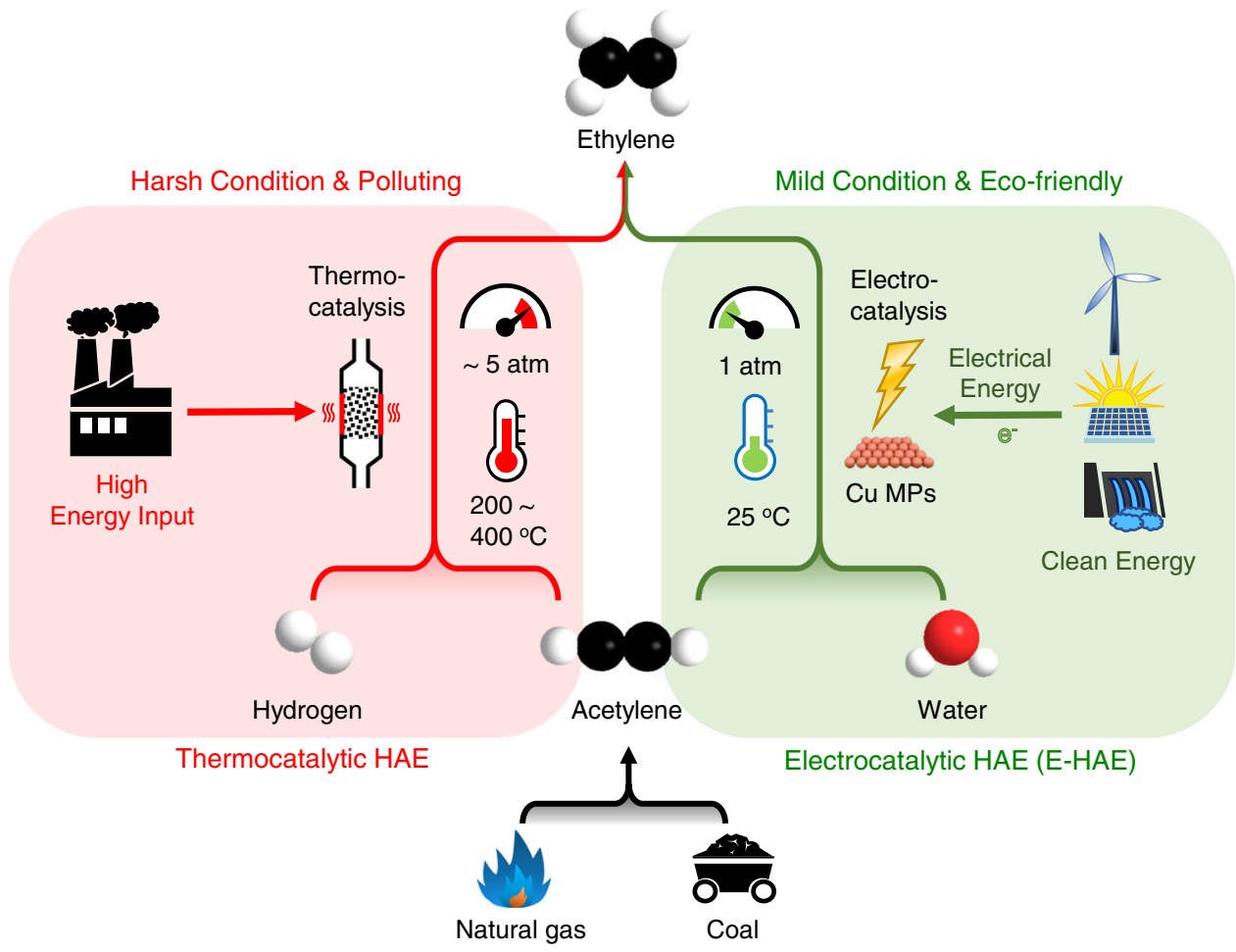

Fig. 1 The features of the electrocatalytic HAE (E-HAE) process compared with the traditional thermocatalytic HAE process. The E-HAE process is more economical and environmental-friendly, operatable under mild reaction conditions with inexpensive water as hydrogen source, in contrast to the thermocatalytic process, which requires harsh reaction conditions and an extra supply of $\mathrm{H}_{2}$. 

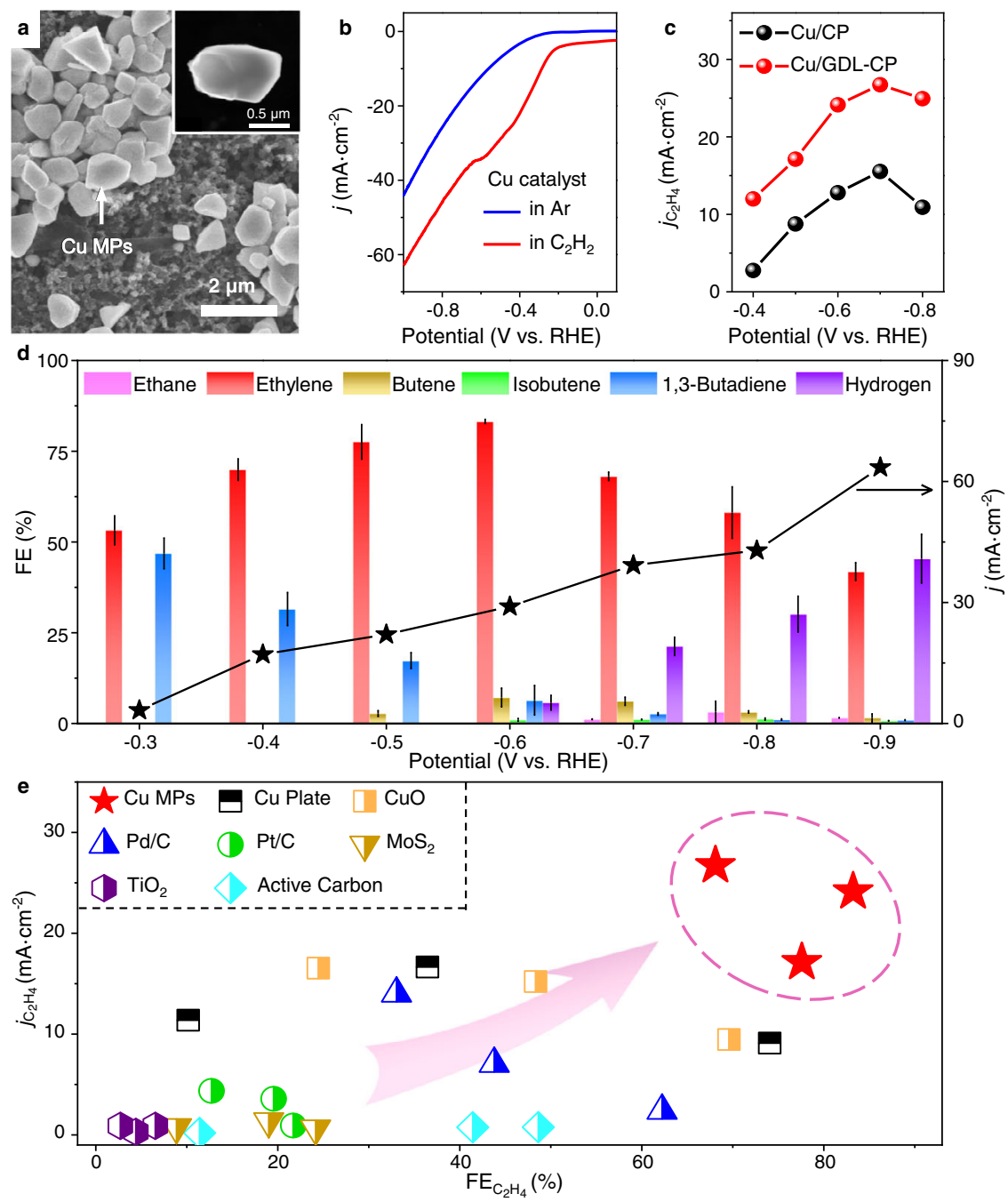

Fig. $\mathbf{2}$ Characterizations of the structure and E-HAE performance of the $\mathbf{C u}$ catalyst. a SEM and HAADF-STEM (inset) image of the catalyst. $\mathbf{b}$ Linear sweep voltammetric curves in $\mathrm{Ar}$-saturated and $\mathrm{C}_{2} \mathrm{H}_{2}$-saturated solution. The scanning rate is $10 \mathrm{mV} \mathrm{s}-1$. c Comparison in the geometric current density of ethylene $\left(\mathrm{j}_{\mathrm{C}_{2} \mathrm{H}_{4}}\right.$ ) over the $\mathrm{Cu}$ microparticles (MPs) loaded on pristine carbon papers ( $\mathrm{Cu} / \mathrm{CP}$ ) and carbon papers coated with the microporous gas diffusion layer (Cu/GDL-CP). d FEs of the E-HAE products and the current densities at different potentials. Error bars correspond to the standard deviation. e Comparison in the FE and the geometric current density for ethylene production from E-HAE over different catalysts, which were tested in this work. All experiments were conducted in $1 \mathrm{M} \mathrm{KOH}$ solution at $25^{\circ} \mathrm{C}$. Source data are provided as a Source Data file.

commercial $\mathrm{Cu}$ bulk according to their normalized peak intensities (Supplementary Fig. 2).

Electrochemical tests were carried out to measure the E-HAE performance of the $\mathrm{Cu}$ MPs loaded on GDL-coated carbon paper $(\mathrm{Cu} / \mathrm{GDL}-\mathrm{CP})$. The linear sweep voltammetry (LSV) was performed to assess the E-HAE activity of the catalyst. In Arsaturated solution, the current density is close to zero even at an electrode potential of $-0.3 \mathrm{~V}$ vs. RHE with or without $i R$ compensation, indicating a poor HER activity of the catalyst. As the solution is saturated by $\mathrm{C}_{2} \mathrm{H}_{2}$, the current density increases remarkably with an onset potential of around -0.24 and $-0.15 \mathrm{~V}$ before and after the $i R$ compensation, respectively (Fig. $2 \mathrm{~b}$ and Supplementary Fig. 3), owing to the contribution of electrocatalytic hydrogenation of acetylene. The different activity of the $\mathrm{Cu}$ MPs for the HER and E-HAE is further confirmed by remeasuring the LSV curves using rotating disk electrode (RDE) instead with loaded catalyst, which present a similar difference in the onset potentials of the two processes (Supplementary Fig. 3), thus demonstrating the higher activity of the catalyst for the E-HAE process.
The microporous GDL, consisting of polytetrafluoroethylene microspheres and hydrophobic carbon particles coated on carbon paper (Supplementary Figs. 4 and 5), plays a significant role in improving the E-HAE reaction efficiency by promoting mass transfer. The GDL is favorable for the formation of gas-liquid-solid interfaces by increasing the hydrophobicity and surface area of electrodes. As indicated in the contact angle tests (Supplementary Fig. 6), the electrode with $\mathrm{Cu} / \mathrm{GDL}-\mathrm{CP}$ is more hydrophobic than the electrode with $\mathrm{Cu}$ MPs loaded on pristine carbon paper $(\mathrm{Cu} / \mathrm{CP})$ (Supplementary Fig. 7$)$. The BET specific surface area (SSA) measurements show that the GDL also remarkably increases the SSA of the CP from 0.37 to $4.55 \mathrm{~m}^{2} \mathrm{~g}^{-1}$, which is favorable for constructing gas-liquid-solid interfaces. Though the $\mathrm{Cu} / \mathrm{GDL}-\mathrm{CP}$ and $\mathrm{Cu} / \mathrm{CP}$ have similar electrochemical active surface areas (ECSAs), which were measured as 6.2 and $6.4 \mathrm{~cm}^{2}$, respectively (Supplementary Fig. 8), the geometric current densities of acetylene consumption $\left(j_{\mathrm{C}_{2} \mathrm{H}_{2}}\right)$ and ethylene formation $\left(j_{\mathrm{C}_{2} \mathrm{H}_{4}}\right)$ on the $\mathrm{Cu} / \mathrm{GDL}-\mathrm{CP}$ are always notably higher than those on the $\mathrm{Cu} / \mathrm{CP}$ (Supplementary Fig. 9, Fig. 2c). Moreover, the FEs of HER on the $\mathrm{Cu} / \mathrm{GDL}-\mathrm{CP}$ at different 
potentials are obviously lower than those on the $\mathrm{Cu} / \mathrm{CP}$, especially at potentials below $-0.6 \mathrm{~V}$ vs. RHE (Supplementary Fig. 10). These results indicate that the GDL can effectively promote the E-HAE process and suppress the HER.

The distribution of products strongly depends on the electrode potential (Fig. 2d). At $-0.3 \mathrm{~V}$ vs. RHE, ethylene and 1,3butadiene are the main products with $\mathrm{FEs}$ of around $53 \%$ and $47 \%$, respectively. With the decrease in potential, the $\mathrm{FE}_{\mathrm{C}_{2} \mathrm{H}_{4}}$ grows gradually and reaches a maximum of $83.2 \%$ at $-0.6 \mathrm{~V}$ with an overall current density of $29 \mathrm{~mA} \mathrm{~cm}^{-2}$, while the FE of 1,3butadiene decreases significantly to below $10 \%$ with few butene generated. Note that the excessive hydrogenation of acetylene to ethane is fully avoided at cathode potentials above $-0.6 \mathrm{~V}$. As the potential becomes more negative, $\mathrm{H}_{2}$ and some deep hydrogenated products such as ethane begin to form, leading to decreased $\mathrm{FE}_{\mathrm{C}_{2} \mathrm{H}_{4}}$. These results show that the electrochemical reductivity strongly depends on the electrode potential, which determines the selectivity of the reduction products. At the potential of $-0.7 \mathrm{~V}$, the rate of acetylene consumption $\left(r_{\text {ace }}\right)$ and geometric $j_{\mathrm{C}_{2} \mathrm{H}_{4}}$ reach maxima of $0.59 \mathrm{mmol} \mathrm{cm}^{-2} \mathrm{~h}^{-1}$ and $26.7 \mathrm{~mA} \mathrm{~cm}^{-2}$, respectively (Supplementary Fig. 11 and Fig. 2c), with acetylene conversion of around $4.9 \%$. Compared with other tested and reported catalysts, the $\mathrm{Cu}$ MPs in this work exhibits the highest $\mathrm{FE}_{\mathrm{C}_{2} \mathrm{H}_{4}}$ and geometric $j_{\mathrm{C}_{2} \mathrm{H}_{4}}$ for the E-HAE (Fig. 2e, Supplementary Table 1$)^{16-18}$. Moreover, by tandemly connecting more electrolytic cells with adjusted flow rate to $2.4 \mathrm{~mL} / \mathrm{min}$, the conversion of acetylene can be further increased to $9.3 \%$ in a single-cell system, and to $17.6 \%$ in a double-cell system and $23.3 \%$ in a triple-cell system (Supplementary Fig. 12), where the reaction rate of acetylene can still reach $0.45 \mathrm{mmol} \mathrm{cm}^{-2} \mathrm{~h}^{-1}$ with ethylene selectivity of over $80 \%$ and ethylene Faradaic efficiency of around $50 \%$. This exhibits the potential of the E-HAE process for industrial applications.

Long-term stability of the $\mathrm{Cu}$ catalyst was measured at the potential of $-0.6 \mathrm{~V}$ vs. RHE. The $\mathrm{FE}_{\mathrm{C}_{2} \mathrm{H}_{4}}$ can be well-maintained above $70 \%$ for over $100 \mathrm{~h}$ with a current density of around $12 \mathrm{~mA} \mathrm{~cm}^{-2}$ (Supplementary Fig. 13). The activity loss may be due to partial blocking of active sites by the formed polyacetylene layer on the catalyst surface, as detected by TEM and Raman spectroscopy showing the feature peaks of polyacetylene at 1102 and $1492 \mathrm{~cm}^{-1}$ (Supplementary Figs. 14 and 15) 22 .

Electronic property of the $\mathrm{Cu}$ catalyst. In-situ X-ray absorption fine structure (XAFS) experiments were performed to investigate the electronic and geometric properties of the $\mathrm{Cu}$ catalyst ${ }^{23}$. The reaction was carried out in a specially designed H-type cell (Fig. 3a and Supplementary Fig. 16). The profile of the X-ray absorption near-edge structure (XANES) spectra of the $\mathrm{Cu}$ $\mathrm{K}$-edge under different conditions all resemble that of the $\mathrm{Cu}$ foil with white lines slightly shifted to higher energies, thus indicating a mild oxidization state of the $\mathrm{Cu}$ catalyst which may be attributed to exposure of the catalyst to air (Fig. 3b). At cathodic potential of $-0.6 \mathrm{~V}$ vs. RHE in Ar-saturated electrolyte, the white line shifts back to a lower energy in contrast to that at opencircuit potential (OCP), which indicates a reduction of the catalyst surface by the electrode potential. In $\mathrm{C}_{2} \mathrm{H}_{2}$-saturated electrolyte, the white lines shift again to a higher energy relative to those in the Ar-saturated electrolyte at $-0.6 \mathrm{~V}$ or OCP (Fig. 3b), which was also observed and confirmed at other reaction potentials of -0.4 and $-0.8 \mathrm{~V}$ (Supplementary Fig. 17). The DFTsimulated $\mathrm{Cu}$ K-edge XANES spectra also show that all the absorption edges of the surface $\mathrm{Cu}$ atoms on $\mathrm{Cu}(100),(110)$, and (111) shift to higher binding energies after the adsorption of $\mathrm{C}_{2} \mathrm{H}_{2}$ on the surfaces (Supplementary Fig. 18). This indicates that the $\mathrm{C}_{2} \mathrm{H}_{2}$ adsorption on the surface leads to increased oxidation state of the catalyst owing to the electron transfer from $\mathrm{Cu}$ to antibonding $\pi$ orbital of the adsorbed $\mathrm{C}_{2} \mathrm{H}_{2}\left({ }^{*} \mathrm{C}_{2} \mathrm{H}_{2}\right)^{24}$. This result is also confirmed by in-situ Raman spectroscopy characterizations at OCP (Fig. 3c), in which the significant peak at $1690 \mathrm{~cm}^{-1}$ assigned to the carbon-carbon triple bond of ${ }^{*} \mathrm{C}_{2} \mathrm{H}_{2}$ on the $\mathrm{Cu}$ surface in $\mathrm{C}_{2} \mathrm{H}_{2}$-saturated solution, is remarkably red-shifted relative to that of the gas phase $\mathrm{C}_{2} \mathrm{H}_{2}{ }^{25}$. Thereby, the $\mathrm{C}-\mathrm{C}$ bond of the ${ }^{*} \mathrm{C}_{2} \mathrm{H}_{2}$ is likely weakened and activated due to the filling of antibonding orbital by the electrons transferred from $\mathrm{Cu}$. The corresponding Fourier-transformed extended XAFS spectra in the R-space for the $\mathrm{Cu}$ MPs catalyst before and after the reaction, are almost identical and are quite similar with that for the $\mathrm{Cu}$ foil (Supplementary Fig. 19), thus indicating a high stability of the catalyst during the E-HAE process.

Reaction intermediates in the E-HAE. To investigate the reaction intermediates during the E-HAE, we carried out the in-situ attenuated total reflectance-Fourier transform infrared (ATR-FTIR) spectroscopy characterizations, which is highly sensitive to surface species $^{26,27}$. The in-situ ATR-FTIR spectrum at different potentials are plotted in Fig. $3 \mathrm{~d}$. At $-0.1 \mathrm{~V}$ vs. RHE, a positive peak at $1630 \mathrm{~cm}^{-1}$ and two negative peaks at 1594 and $1670 \mathrm{~cm}^{-1}$ were observed. The positive peak at $1630 \mathrm{~cm}^{-1}$ is assigned to the desorbed $\mathrm{H}_{2} \mathrm{O}$ from the catalyst surface ${ }^{28}$. The negative band at $1594 \mathrm{~cm}^{-1}$ is assigned to the generated ${ }^{*} \mathrm{CH}=\mathrm{CH}_{2}\left({ }^{*} \mathrm{C}_{2} \mathrm{H}_{3}\right)$, a reaction intermediate of $\mathrm{C}_{2} \mathrm{H}_{2}$ reduction ${ }^{29,30}$. The peak at $1670 \mathrm{~cm}^{-1}$ is assigned to the ${ }^{*} \mathrm{C}_{2} \mathrm{H}_{2}$ on the $\mathrm{Cu}$ surface, which is close to that of the in-situ Raman spectrum (Fig. 3c). As the electrode potential becomes more negative, the peak of ${ }^{*} \mathrm{C}_{2} \mathrm{H}_{3}$ at $1594 \mathrm{~cm}^{-1}$ increases prominently, indicating that hydrogenation of the ${ }^{*} \mathrm{C}_{2} \mathrm{H}_{2}$ to ${ }^{*} \mathrm{C}_{2} \mathrm{H}_{3}$ is strongly related to the electrode potential and the ${ }^{*} \mathrm{C}_{2} \mathrm{H}_{3}$ is the key intermediate for the formation of $\mathrm{C}_{2} \mathrm{H}_{4}$. The evolution of surface species was further validated using a reversed sweeping of potential from -0.9 to $0.1 \mathrm{~V}$ with an interval of $0.2 \mathrm{~V}$ (Supplementary Fig. 20), which shows a reversed change in the peak intensities. According to these results, the possible reaction routes in the $\mathrm{E}-\mathrm{HAE}$ on the $\mathrm{Cu}$ catalyst are proposed (Fig. 3e): acetylene is firstly hydrogenated to ${ }^{*} \mathrm{C}_{2} \mathrm{H}_{3}$ intermediate, which then undergoes further hydrogenation to ethylene, or coupling and hydrogenation to 1,3-butadiene by-product.

Understanding the reaction mechanism. DFT calculations were carried out to gain further insights into the active sites and the reaction mechanism of the E-HAE process over the $\mathrm{Cu}$ catalyst. Three crystal facets of $\mathrm{Cu}$ including (111), (100), and (110) were considered according to the XRD analysis (Supplementary Fig. 2). On all these surfaces, $\mathrm{C}_{2} \mathrm{H}_{2}$ prefers to be strongly adsorbed on the hollow sites with much higher adsorption free energies compared with hydrogen adsorption (Supplementary Fig. 21). Bader charge analysis shows a significant decrease in the valence electrons of the $\mathrm{Cu}$ atoms with an increase of up to 0.65 electrons on the ${ }^{*} \mathrm{C}_{2} \mathrm{H}_{2}$, thus demonstrating the electron transfer from the $\mathrm{Cu}$ surface to the ${ }^{*} \mathrm{C}_{2} \mathrm{H}_{2}$ which is in consistency with the experimental results as discussed above. The electron transfer can be more clearly visualized in the differential charge density of the adsorption structure (Fig. 4a), showing charge depletion areas around the $\mathrm{Cu}$ adsorption sites and charge accumulation areas around the ${ }^{*} \mathrm{C}_{2} \mathrm{H}_{2}$ on the $\mathrm{Cu}$ surfaces. Considering the strong adsorption of $\mathrm{C}_{2} \mathrm{H}_{2}$, the surface coverage effect of $\mathrm{C}_{2} \mathrm{H}_{2}$ was included in studying the reaction mechanism. Equilibrium coverages of 1.0, 1.0, and 0.5 monolayer $\mathrm{C}_{2} \mathrm{H}_{2}$ was obtained on the $\mathrm{Cu}(100),(110)$, and (111) surfaces, respectively, by calculating the adsorption free energy $\left(\Delta G_{\mathrm{ads}}\right)$ of $\mathrm{C}_{2} \mathrm{H}_{2}$ on the gradually covered surfaces until no further adsorption is favorable (Fig. 4b, Supplementary Fig. 22). The electrochemical 
a

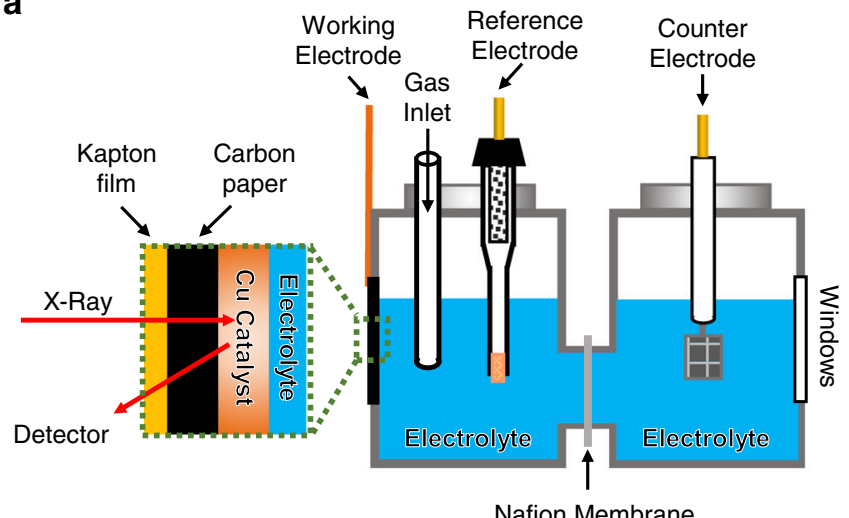

b

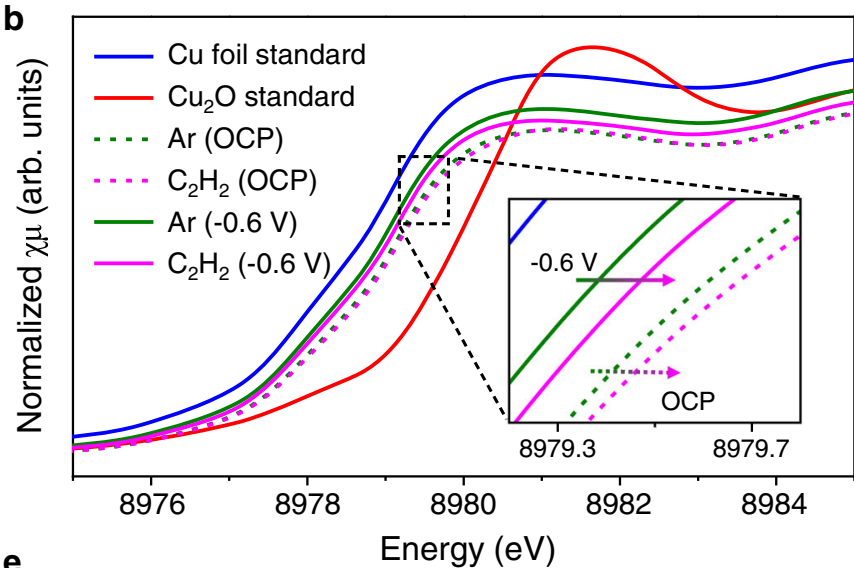

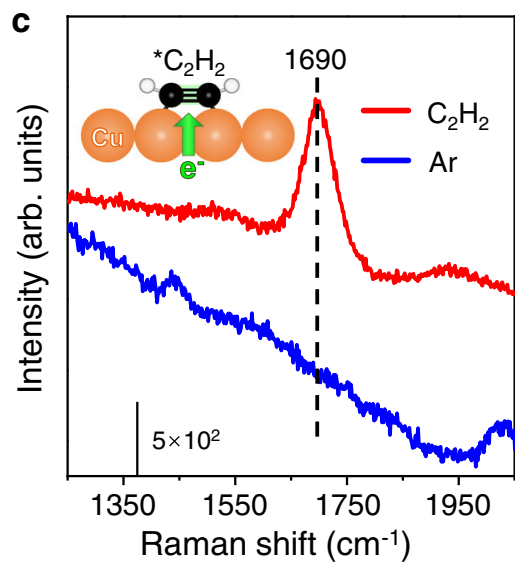

d

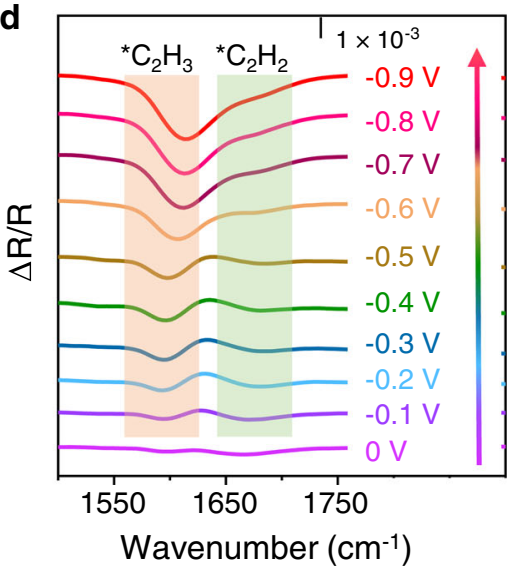

i)

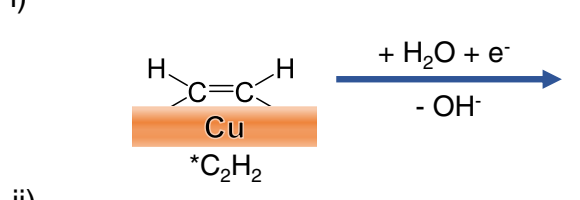

ii)<smiles>CC=CC(C)(C)C</smiles>

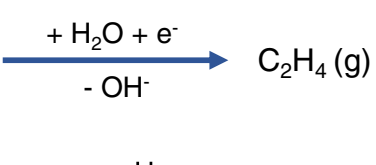

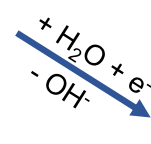

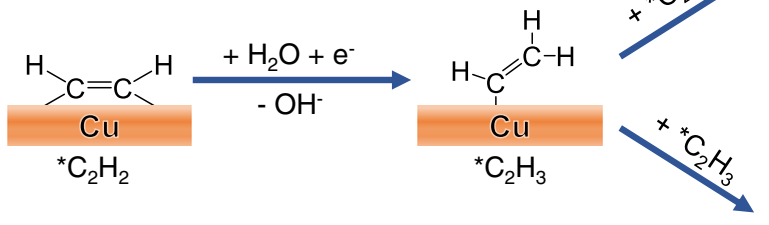

\section{$\mathrm{C}_{4} \mathrm{H}_{6}(\mathrm{~g})$}

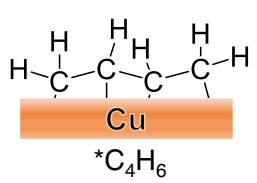

Fig. 3 In-situ spectroscopic characterizations of the Cu catalyst and the reaction intermediates. a The schematic illustration of in-situ XANES electrolytic cell. $\mathbf{b}$ The in-situ Cu K-edge XANES of the catalyst in Ar-saturated and $\mathrm{C}_{2} \mathrm{H}_{2}$-saturated solution at OCP and -0.6 V, compared with those of Cu foil and $\mathrm{Cu}_{2} \mathrm{O}$ standard sample. c The in-situ Raman spectra of the catalyst in Ar-saturated solution and $\mathrm{C}_{2} \mathrm{H}_{2}$-saturated solution. $\mathbf{d}$ The in-situ ATR-FTIR spectra during the E-HAE process at potentials from $\mathrm{O}$ to $-0.9 \mathrm{~V}$ in $\mathrm{C}_{2} \mathrm{H}_{2}$-saturated solution. The reflection intensity is decreased due to infrared absorption of surface species; thus, the generation of species leads to a negative peak. $\mathbf{e}$ The proposed reaction routes for the formation of (i) ethylene and (ii) 1,3-butadiene. All the potentials in the figures are referenced to the RHE. The in-situ XANES and Raman experiments were conducted in $1 \mathrm{M}$ KOH solution at $25^{\circ} \mathrm{C}$. The in-situ ATR-FTIR experiments were conducted in $0.1 \mathrm{M} \mathrm{KOH}$ solution at $25^{\circ} \mathrm{C}$. Source data are provided as a Source Data file.

hydrogenation reaction mechanism was then investigated on the $\mathrm{C}_{2} \mathrm{H}_{2}$-covered surfaces.

The formation of surface $\mathrm{H}$ species $\left({ }^{*} \mathrm{H}\right)$ on the $\mathrm{C}_{2} \mathrm{H}_{2}$-covered surfaces is energetically unfavorable with $\Delta G_{\text {ads }}$ of $0.56,0.17$, and $0.49 \mathrm{eV}$ on the $\mathrm{Cu}(100)$, (110), and (111) surfaces, respectively (Fig. 4c). In addition, the formation process of ${ }^{*} \mathrm{H}$ via electron-coupled proton transfer from the water layer to the $\mathrm{C}_{2} \mathrm{H}_{2}$-covered surfaces also requires high barriers of approximately $0.81,1.84$, and $0.97 \mathrm{eV}$ on the $\mathrm{Cu}(100)$, (110), and (111) surfaces, respectively. These results demonstrate that ${ }^{*} \mathrm{H}$ can hardly be formed on the $\mathrm{C}_{2} \mathrm{H}_{2}$-covered $\mathrm{Cu}$ surfaces, which could explain the poor HER activity at potentials above $-0.6 \mathrm{~V}$ vs. RHE. 
a
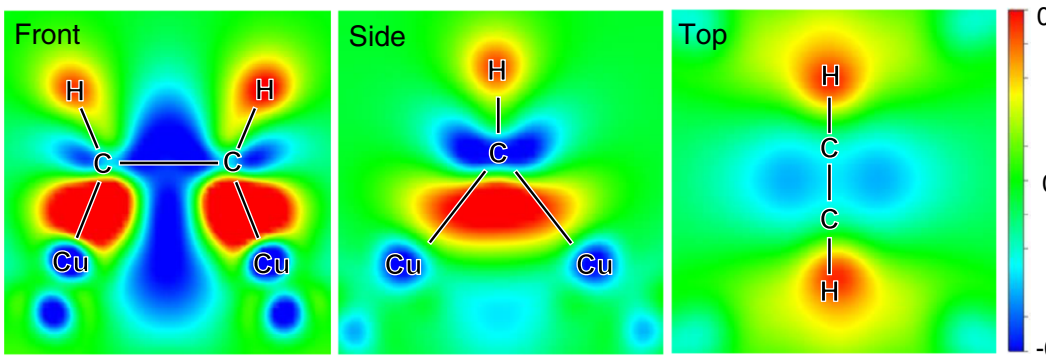

0.05

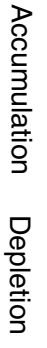

b

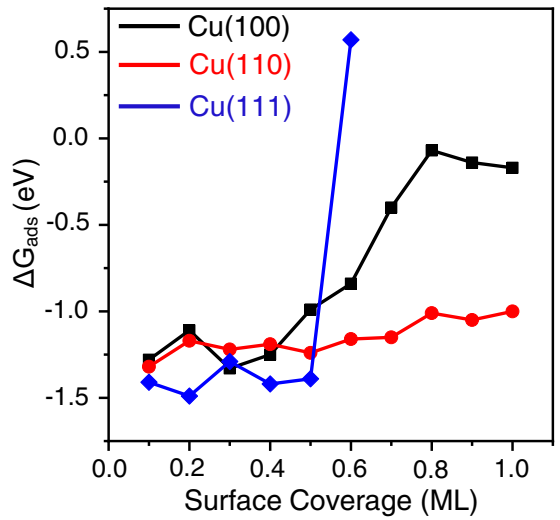

c

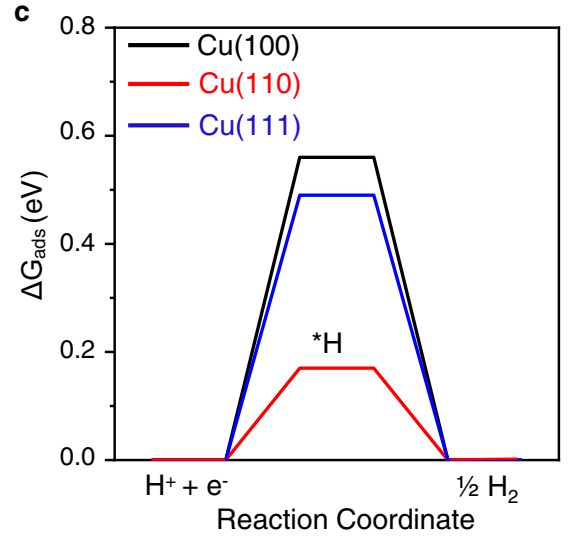

d

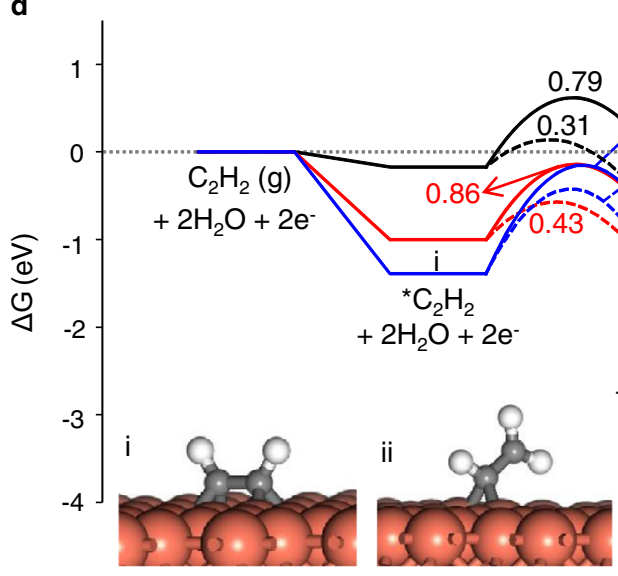

$-\mathrm{Cu}(100)$
$-\mathrm{Cu}(110)$ 
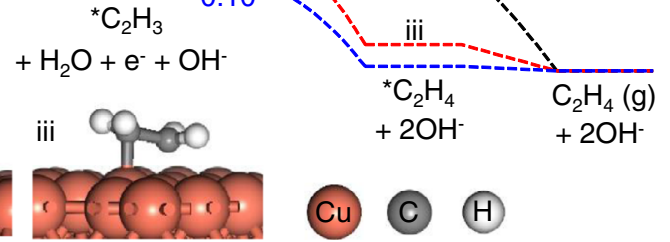

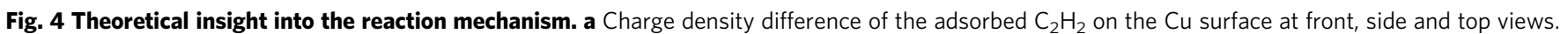

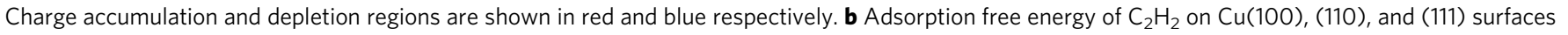

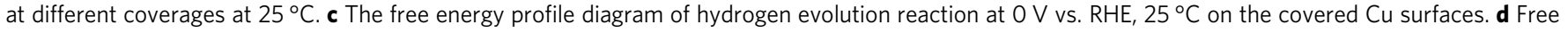

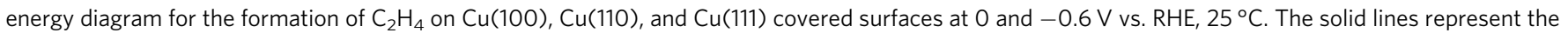

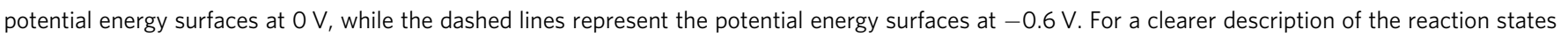

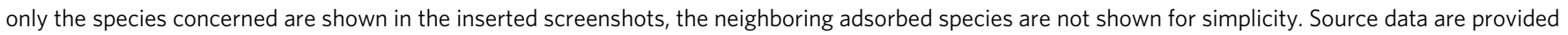
as a Source Data file.

This also indicates that the ${ }^{*} \mathrm{C}_{2} \mathrm{H}_{2}$ is not likely hydrogenated by surface ${ }^{*} \mathrm{H}$, but rather via electron-coupled proton transfer from the water layer (Eq. 1), as also reflected by the $\mathrm{pH}$ effect on the overall Faradaic efficiencies for acetylene hydrogenation and $\mathrm{HER}$, where a lower $\mathrm{pH}$ is more favorable for the hydrogenation of acetylene than the HER (Supplementary Fig. 23).

$$
{ }^{*} \mathrm{C}_{\mathrm{x}} \mathrm{H}_{\mathrm{y}}+\mathrm{H}_{2} \mathrm{O}+\mathrm{e}^{-} \rightarrow{ }^{*} \mathrm{C}_{\mathrm{x}} \mathrm{H}_{\mathrm{y}+1}+\mathrm{OH}^{-}
$$

The free energy reaction pathways for the formation of $\mathrm{C}_{2} \mathrm{H}_{4}$ on the three $\mathrm{Cu}$ surfaces were calculated as shown in Fig. $4 \mathrm{~d}$ and Supplementary Table 2. Hydrogenation of the ${ }^{*} \mathrm{C}_{2} \mathrm{H}_{2}$ to ${ }^{*} \mathrm{C}_{2} \mathrm{H}_{3}$ is the rate-limiting step on all the three surfaces with barriers of $0.79,0.86$, and $1.24 \mathrm{eV}$ on the (100), (110), and (111) surfaces at $0 \mathrm{~V}$ vs. RHE, respectively. The highest barrier for the first hydrogenation step on the $\mathrm{Cu}(111)$ surface may be due to the much stronger adsorption of $\mathrm{C}_{2} \mathrm{H}_{2}$ on the surface (Fig. $4 \mathrm{~b}$ ). The second hydrogenation steps all proceed with relatively lower barriers and the generated $\mathrm{C}_{2} \mathrm{H}_{4}$ can be easily desorbed from the surfaces, which are kinetically more favorable than the further hydrogenation step via the electron-coupled proton transfer and thereby suppresses the excessive hydrogenation pathway. Formation of $\mathrm{C}_{4} \mathrm{H}_{6}$ was also investigated which involves both electrochemical hydrogenation steps and non-electrochemical carbon-carbon $(\mathrm{C}-\mathrm{C})$ coupling steps, and thus can occur in two pathways: coupling of $* \mathrm{C}_{2} \mathrm{H}_{3}$ and $* \mathrm{C}_{2} \mathrm{H}_{2}$ (First pathway) or two ${ }^{*} \mathrm{C}_{2} \mathrm{H}_{3}$ (Second pathway) (Supplementary Figs. 24 and 25, Supplementary Tables 3 and 4). Both reaction pathways have relatively lower barriers on the $\mathrm{Cu}(100)$ surface, which should be due to the relatively weaker adsorption of reaction intermediates on the $\mathrm{C}_{2} \mathrm{H}_{2}$-covered (100) surface. 
The high selectivity of $\mathrm{C}_{2} \mathrm{H}_{4}$ against $\mathrm{C}_{4} \mathrm{H}_{6}$ is largely affected by the applied negative potential as shown in Fig. $2 \mathrm{~d}$, in contrast with the selectivity at $0 \mathrm{~V}$ vs. RHE. This is because the electrochemical hydrogenation steps involve significant electron transfer and are potential-dependent. The applied negative potentials lead to lowered work function of the surface, which could stabilize the transition states (TSs) and thereby reduce the energy barriers ${ }^{31}$. At $-0.6 \mathrm{~V}$ vs. RHE, the activation energies of the electrochemical hydrogenation steps are significantly reduced compared with those at $0 \mathrm{~V}$, especially for the rate-limiting ${ }^{*} \mathrm{C}_{2} \mathrm{H}_{2}$ hydrogenation to ${ }^{*} \mathrm{C}_{2} \mathrm{H}_{3}$, the activation energies of which on the (100) and (110) surfaces are more reduced and become even comparable with those of other steps (Fig. 4d, Supplementary Figs. 24 and 25, Supplementary Tables 2-4). Therefore, by adjusting the electrode potential, the potential-dependent electrochemical hydrogenation steps can be promoted over the potential-independent non-electrochemical $\mathrm{C}-\mathrm{C}$ coupling steps, thereby increasing the selectivity of $\mathrm{C}_{2} \mathrm{H}_{4}$ on the $\mathrm{Cu}$ catalyst.

In conclusion, we reported a highly efficient electrocatalytic process for acetylene hydrogenation via using the $\mathrm{Cu}$ catalyst at room temperature and ambient pressure. By adjusting the electrode potential as well as using the GDL to promote mass transfer, a highest $\mathrm{FE}_{\mathrm{C}_{2} \mathrm{H}_{4}}$ of $83.2 \%$ was reached at $-0.6 \mathrm{~V}$ vs. RHE, and a highest geometric $j_{\mathrm{C}_{2} \mathrm{H}_{4}}$ of $26.7 \mathrm{~mA} \mathrm{~cm}^{-2}$ was reached at $-0.7 \mathrm{~V}$, which are better than those of other tested and previously reported catalysts. Moreover, during the 100-h stability test, the $\mathrm{Cu}$ catalyst shows a good performance. The in-situ characterizations and DFT calculations confirm that electron transfer from the $\mathrm{Cu}$ surface to the acetylene enhances the adsorption of acetylene against hydrogen, which suppresses the HER while promoting the E-HAE through the electron-coupled proton transfer mechanism. The E-HAE process reported in this work provides new prospect for developing energy-efficient and eco-friendly ways of ethylene production.

\section{Methods}

Preparation of catalysts. All chemicals were used without further purification. Ethylene glycol (EG) was purchased from Sigma-Aldrich. Copper sulfate pentahydrate $\left(\mathrm{CuSO}_{4} \cdot 5 \mathrm{H}_{2} \mathrm{O}\right)$, ascorbic acid (AA), NaOH, NaCl, ethanol, and polyvinyl pyrrolidone (PVP) K-30 were bought from Sinopharm Chemical Reagent Co. Ltd. $\mathrm{Pt} / \mathrm{C}$ was produced by Johnson Matthey. Pd/C was bought from J\&K Scientific Ltd. The $\mathrm{TiO}_{2}$ (P25) was purchased from Degussa. Active carbon was purchased from Sigma-Aldrich. The Cu plate was purchased from Shichun Co. The characterizations of catalysts were presented in Supplementary Figs. 26-29.

To synthesize the $\mathrm{Cu}$ MPs, $125 \mathrm{mg} \mathrm{CuSO} \cdot 5 \mathrm{H}_{2} \mathrm{O}$ and $200 \mathrm{mg}$ PVP were dissolved in a flask containing $20 \mathrm{~mL}$ EG. Then $0.2 \mathrm{~mL} 1 \mathrm{M} \mathrm{NaCl}$ EG solution was added into the flask. Then the mixture was preheated to $100^{\circ} \mathrm{C}$. Next, another mixture of $1 \mathrm{~mL} 1 \mathrm{M} \mathrm{NaOH}$ and $2.5 \mathrm{~mL} 0.5 \mathrm{M}$ AA EG solution was injected into the flask for $10 \mathrm{~min}$. Then the mixture was heated for $40 \mathrm{~min}$ in $100^{\circ} \mathrm{C}$. Then the $\mathrm{Cu}$ MPs were cleaned using a mixture of alcohol and water by centrifuge. Finally, the $\mathrm{Cu}$ MPs were kept in alcohol in the freezer of a refrigerator.

The $\mathrm{CuO}$ was synthesized by heating the $\mathrm{Cu}$ MPs at $500^{\circ} \mathrm{C}$ for $1 \mathrm{~h}$ under $20 \%$ $\mathrm{O}_{2} / \mathrm{Ar}$ (Supplementary Fig. 30). The $\mathrm{MoS}_{2}$ catalyst was synthesized by using our previously reported method (Supplementary Fig. 31). Typically, $900 \mathrm{mg}$ $\left(\mathrm{NH}_{4}\right)_{6} \mathrm{Mo}_{7} \mathrm{O}_{24} \cdot 4 \mathrm{H}_{2} \mathrm{O}$ was dissolved in $20 \mathrm{~mL}$ deionized water. Then, this solution and $10 \mathrm{ml} \mathrm{CS}_{2}$ were sealed in a $40 \mathrm{~mL}$ stainless-steel autoclave under Ar protection and maintained at $400{ }^{\circ} \mathrm{C}$ for $4 \mathrm{~h}$. The Cu plate was cut into " $\mathrm{L}$ " shape with a $1 \times 1 \mathrm{~cm}^{2}$ square and a $0.5 \times 1 \mathrm{~cm}^{2}$ bar. The $\mathrm{Cu}$ plate was polished by silicon carbide papers, followed by alumina polishing powder $(1 \mu \mathrm{m}, 0.05 \mu \mathrm{m})$.

Characterization. SEM characterizations were conducted on Hitachi S4800. TEM measurements were conducted on the FEI Tecnai F20 and FEI talos F200X microscopes operated at an accelerating voltage of $200 \mathrm{kV}$. To prepare the TEM sample, $100 \mu \mathrm{L} \mathrm{Cu}$ MPs ink was dispersed in $3 \mathrm{~mL}$ ethanol and treated with ultrasound for $0.5 \mathrm{~h}$; then the solution was dropped on a Cu net for TEM and then dried by a heating light for $10 \mathrm{~min}$. The XRD measurements were carried out on a Rigaku Ultima IV diffractometer with $\mathrm{Cu} \mathrm{Ka}$ radiation at $40 \mathrm{kV}$ and $30 \mathrm{~mA}$.

E-HAE reaction performance test. The $4 \mathrm{mg}$ catalysts mixed with $9 \mu \mathrm{L}$ Nafion solution (5 wt\%, Du Pont) and drip-coated on carbon paper with the GDL-CP (AvCarb GDS3250 with micro-porous layer) were used as the working electrode.
The carbon paper was cut into an " $L$ " shape with a $1 \times 1 \mathrm{~cm}^{2}$ square and a $0.5 \times 1 \mathrm{~cm}^{2}$ bar (Supplementary Fig. 32a, c). Totally, $4 \mathrm{mg} \mathrm{Cu}$ MPs were dispersed in $0.5 \mathrm{~mL}$ ethanol and were dripped on the $1 \times 1 \mathrm{~cm}^{2}$ square part, which was dried under a heating light (Supplementary Fig. 32b, d). The electrode is fixed by the electrode holder via the bar. Only the $1 \times 1 \mathrm{~cm}^{2}$ square part of carbon paper with catalysts was immersed in the electrolyte. New working electrodes were prepared for every electrochemical measurement. The electrode was kept in a vacuum drier before use. Alkaline aqueous solutions with $\mathrm{KOH}$ concentration of $0.1,1$, and $3 \mathrm{M}$ were used as the electrolyte. The electrocatalytic performances were measured on a $\mathrm{CHI}$ 660e with a H-type electrochemical cell equipped with a flow-controlling device. The anode and cathode electrode chambers were divided by the Nafion-115 membrane. The reference electrode is the $\mathrm{Hg} / \mathrm{HgO}$ electrode filled with $1 \mathrm{M} \mathrm{KOH}$. All potentials were measured against the $\mathrm{Hg} / \mathrm{HgO}$ (filled with $1 \mathrm{M} \mathrm{KOH}$ ), which were then converted to be versus the RHE by the equation $\mathrm{U}$ (vs. RHE) $=\mathrm{U}$ (vs. Hg/ $\mathrm{HgO}, 1 \mathrm{M} \mathrm{KOH})+0.098 \mathrm{~V}+0.059 \times \mathrm{pH}$. The potential of the $\mathrm{Hg} / \mathrm{HgO}$ electrode relative to the RHE was $0.924 \mathrm{~V}$. The Pt net was used as the counter electrode. Before the test, the cyclic voltammetry $\left(-0.1\right.$ to $-0.6 \mathrm{~V}$ vs. RHE, $0.5 \mathrm{~V} \mathrm{~s}^{-1}$, 40 cycles) was carried out in the Ar-saturated solution. During the test, the acetylene was kept bubbling into the cell. In a typical experiment, the reaction at each potential was carried out for $2 \mathrm{~h}$ before analyzing the products. For the analysis with $i R$ compensation, a $90 \% i R$ compensation was used. The $R$ for $i R$ correction was determined by impedance measurements.

The diameter of the RDE is $5 \mathrm{~mm}$. The surface area of the electrode is $0.196 \mathrm{~cm}^{2}$. The surface of glassy carbon was polished by aluminia polishing powder $(0.05 \mu \mathrm{m})$. Totally, $2 \mathrm{mg} \mathrm{Cu}$ MPs was suspended in $0.5 \mathrm{~mL}$ ethanol with $10 \mu \mathrm{L}$ Nafion solution to form a homogeneous ink by ultrasound. Then $25 \mu \mathrm{L}$ of the ink was drop-casted onto the surface of glassy carbon. The rotation rate is $2500 \mathrm{rpm}$ during the tests.

ECSAs of the $\mathrm{Cu}$ MPs catalyst were measured by using the $\mathrm{Pb}$ underpotential deposition method in solution with $10 \mathrm{mM} \mathrm{Pb}\left(\mathrm{ClO}_{4}\right)_{2}$ and $0.1 \mathrm{M} \mathrm{HClO}_{4}{ }^{32,33} \cdot \mathrm{N}_{2}$ was kept bubbling into the system to avoid the effect of $\mathrm{O}_{2}$. The $1 \times 1 \mathrm{~cm}^{2}$ square part of the electrode was immersed in the solution. The cyclic voltammetry test was repeated from -0.375 to $-0.005 \mathrm{~V}$ vs. $\mathrm{Ag} / \mathrm{AgCl}$ at $10 \mathrm{mV} / \mathrm{s}$ until reproducible voltammograms were obtained. The number of charges consumed for the oxidation of $\mathrm{Pb}$ atoms was determined by integrating the anodic shadow area as shown in Supplementary Fig. 8. A conversion factor of $310 \mu \mathrm{C} \mathrm{cm}^{-2}$ was used for $\mathrm{Pb}$ oxidation ${ }^{34}$

In-situ XANES. XANES spectra were measured at the BL14W1 beamline of the Shanghai Synchrotron Radiation Facility. The specially designed H-type cell was used as the electrolytic cell. The electrode settings and reaction conditions were kept the same as those in the reaction performance tests. In situ XANES spectra was collected at OCP after bubbling Ar or acetylene for $20 \mathrm{~min}$. The gas was kept bubbling into the cell during the measurements. The potential was set at $-0.6 \mathrm{~V}$ vs. RHE for 10 min before recording the XANES spectra.

In-situ Raman. Raman spectra were measured with a Xplora confocal microprobe Raman system (HORIBA JobinYvon) equipped with a $50 \times$ microscope objective. The working electrode was glassy carbon loaded with $\mathrm{Cu}$ MPs. The $\mathrm{Hg} / \mathrm{HgO}$ electrode (filled with $1 \mathrm{M} \mathrm{KOH}$ ) and the Pt wire were used as the reference electrode and the counter electrode, respectively. $1 \mathrm{M} \mathrm{KOH}$ solution was used as the electrolyte. A laser with a wavelength of $637 \mathrm{~nm}$ was used as the excitation source. The power of the laser was about $6 \mathrm{~mW}$. A Si wafer was used to calibrate Raman frequencies. The collection time of each spectrum was over $15 \mathrm{~s}$. Each spectrum was obtained as an average of twice measurements.

In-situ ATR-FTIR. A Nexus-870 spectrometer was used to measure the ATR-FTIR with an MCT-A detector. The temperature of detector was controlled using liquid nitrogen. The basal plane of a hemicylindrical Si prism beveled at $60^{\circ}$ was deposited on Au film using a chemical method. The catalyst ink was dripped onto the Au film polished by an electrochemical way. $0.1 \mathrm{M} \mathrm{KOH}$ solution was used as the electrolyte. The electrode settings and reaction conditions were kept the same as those in the reaction performance tests. The acetylene was constantly introduced into the cell during the test. The reference spectra were collected at OCP.

Products analysis. The gas-phase products were analyzed by using gas chromatography with $\mathrm{Ar}$ as the carrier gas. The GC-2060 was equipped with an $\mathrm{Al}_{2} \mathrm{O}_{3}$ / $\mathrm{Na}_{2} \mathrm{SO}_{4}$ column (Kromat $50 \mathrm{~m} \times 0.53 \mathrm{~mm} \times 20.00 \mu \mathrm{m}$ ) on a flame ionization detector which can detect hydrocarbon products. The TDX column was equipped in the GC with a thermal conductivity detector which can detect $\mathrm{H}_{2}$. The chromatograph was equipped with a ten-port valve and sample injection loop. During the experiment, the ten-port valve is periodically switched between Position A and Position B (Supplementary Fig. 33). In Position A, the outgoing gas passes through the sample loops and then is vented out. When the ten-ports valve is switched to Position B, the carrier gas brings the sample gas in the sample loops into the chromatography (two columns for TCD and FID, respectively) for analyzing the products. This makes sure that the same volume of gas is injected into the chromatogram in each analysis. The GC measurements were carried out after running the reaction for $2 \mathrm{~h}$. 
A typical GC spectrum is shown in Supplementary Fig. 34. The Faradaic efficiency is calculated using the following equation.

$$
\mathrm{FE}_{\text {(product) }}=\frac{S_{\text {(product) }}}{a} \times v \times t \times \frac{n \mathrm{FP}_{0}}{\mathrm{RT}} \times \frac{1}{\mathrm{Q}}
$$

where, $S_{\text {(product) }}$ is the area of products on the GC spectrum, $a$ is the percentage conversion factor based on standard gas, which converts the peak area to the volume percentage of a single product. $v$ is the gas flow rate, $t$ is the reaction time, $n$ is the moles of charges transfer from reactants to products per mole, $F$ is Faraday's constant $96,485 \mathrm{C} \mathrm{mol}^{-1}$. $Q$ is the total number of charges applied into the system

$P_{0}=101,325 \mathrm{~Pa}, R=8.314 \mathrm{~J} \mathrm{~mol}^{-1} \mathrm{~K}^{-1}$, and $T=298.15 \mathrm{~K}$.

For the experiments, $v=4.8 \mathrm{~mL} \mathrm{~min}^{-1}=0.8 \times 10^{-7} \mathrm{~m}^{3} \mathrm{~s}^{-1} ; t=2 \mathrm{~h}=7200 \mathrm{~s}$. In the experiments with tandemly connected cells, $v$ is adjusted to $2.4 \mathrm{~mL} \mathrm{~min}{ }^{-1}$.

The $j_{\mathrm{C}_{2} \mathrm{H}_{2}}$ and $j_{\mathrm{C}_{2} \mathrm{H}_{4}}$ are calculated using the following equations:

$$
\begin{gathered}
j_{\mathrm{C}_{2} \mathrm{H}_{2}}=\sum_{\text {product }} \mathrm{FE}_{\text {(product) }} \times j \\
j_{\mathrm{C}_{2} \mathrm{H}_{4}}=\mathrm{FE}_{\mathrm{C}_{2} \mathrm{H}_{4}} \times j
\end{gathered}
$$

where $\mathrm{FE}_{\text {(product) }}$ is the Faradaic efficiency of a specific product of the electrochemical acetylene hydrogenation, $\mathrm{FE}_{\mathrm{C}_{2} \mathrm{H}_{4}}$ is the Faradaic efficiency of ethylene formation, and $j$ is the overall current density.

The acetylene reaction rate per unit area $\left(r_{\text {ace }}\right)$ was calculated from the formation rates of products using the following equation:

$$
r_{\text {ace }}=\sum_{\text {product }} \frac{n_{\text {(ace } / \text { product) }} \times \frac{j \times \mathrm{FE}_{\text {(product) }} \times t}{z_{\text {(product) }} \times F}}{t}=\sum_{\text {product }} \frac{n_{\text {(ace } / \text { product) }} \times j \times F E_{(\text {product) }}}{z_{\text {(product) }} \times F}
$$

where $n_{\text {(ace/product) }}$ is the moles of acetylene consumed to produce one mole of a specific product, $j$ is the overall current density, $F E_{\text {(product) }}$ is the Faradaic efficiency of a specific product, $t$ is reaction time $(2 \mathrm{~h}), z_{\text {(product) }}$ is the moles of transferred charges for producing one mole of a specific product, $F$ is the Faraday's constant $96,485 \mathrm{C} \mathrm{mol}^{-1}$.

Meanwhile, none of liquid phase product was detected by nuclear magnetic resonance (Supplementary Fig. 35).

Computational details. First-principles periodic calculations were carried out with the Vienna Ab initio Simulation Package based on DFT methods ${ }^{35,36}$. The Perdew-Burke-Ernzerhof generalized gradient approach ${ }^{37,38}$ was used to define the exchange-correlation potential. The interaction between the atomic cores and electrons was described using the projector augmented wave potential ${ }^{39,40}$. The surface brillouin zone was sampled at $1 \times 1 \times 1 \mathrm{k}$-point. A $400 \mathrm{eV}$ energy cutoff and the force convergence criterion for each relaxed atom below $0.02 \mathrm{eV} / \AA$ were used. Zero-damping DFT-D3 method of Grimme was used for the Van der Waals correction $^{41,42}$. To determine the kinetic barriers for the electron-coupled proton transfer hydrogenation steps, we introduced a water network model in the system above the surface specie to simulate the transfer of a proton from one of the water molecules to the targeted surface specie. TS searches were conducted at the same theoretical level using Fixed Bond Length method as implemented in the Atomic Simulation Environment by determining the highest energy point along the potential energy surface ${ }^{43}$, and were checked with imaginary vibrational frequencies. The $\mathrm{Cu}$ surfaces were built as a four-layer slab in a $6 \times 6$ supercell with the bottom two layers being fixed during optimization. A vacuum thickness larger than $15 \AA$ was used to separate the surface from its periodic image in the direction perpendicular to the surface.

The adsorption energies $\left(\Delta E_{\mathrm{ads}}\right)$ of the adsorbed molecular species were calculated using the equation below

$$
\Delta E_{\text {ads }}=E_{(\text {adsorbate }+ \text { surface })}-E_{\text {(surface) }}-E_{\text {(adsorbate) }}
$$

where $E_{\text {(adsorbate+surface) }}, E_{\text {(surface), }}$ and $E_{\text {(adsorbate) }}$ are the energies of the optimized surface containing the adsorbate, the optimized clean surface and the optimized adsorbate in the gas phase, respectively. In addition, free energy corrections were considered to obtain the adsorption free energy $\left(\Delta G_{\text {ads }}\right)$ and activation free energy $\left(\Delta G_{\text {act }}\right)$ using the expression as follows:

$$
\begin{gathered}
\Delta G_{\text {ads }}=\Delta E_{\text {ads }}+\Delta E_{\mathrm{ZPE}}+\Delta U_{\text {vib }}-T \Delta S \\
\Delta G_{\text {act }}=\Delta E_{\text {act }}+\Delta E_{\mathrm{ZPE}}+\Delta U_{\text {vib }}
\end{gathered}
$$

where $\Delta E_{\text {ads }}$ is the $0 \mathrm{~K}$ adsorption energy, $\Delta E_{\text {act }}$ is the $0 \mathrm{~K}$ activation energy, $\Delta E_{\mathrm{ZPE}}$ represents the change in the zero-point vibrational energy, $\Delta U_{\text {vib }}$ represents the change in the vibrational part of the internal energy, and $\Delta S$ represents the change in the entropy, for the adsorption of the adsorbates or between the TSs and initial states at room temperature $\left(T=25^{\circ} \mathrm{C}\right)$. The calculated vibrational corrections and frequencies are shown in Supplementary Tables 5-17. The surface coverage in ML was defined as

$$
\theta=N_{\mathrm{C}} / \mathrm{NS}_{\mathrm{Cu}}
$$

where $N_{\mathrm{C}}$ and $\mathrm{NS}_{\mathrm{Cu}}$ represent the total number of carbon atoms of the surfaceadsorbed $\mathrm{C}_{2} \mathrm{H}_{2}$ and the number of surface $\mathrm{Cu}$ atoms, respectively.

For an electrochemical reaction

$$
\mathrm{M}^{*}+\mathrm{H}_{(\mathrm{aq})}^{+}+\mathrm{e}^{-} \rightarrow \mathrm{MH}^{*}
$$

the potential dependent reaction free energy change referenced to a RHE using the computational hydrogen electrode approach ${ }^{44}$, is calculated as shown below

$$
\triangle G=G_{\mathrm{MH}^{*}}-G_{\mathrm{M}^{*}}-\frac{1}{2} G_{\mathrm{H}_{2}(g)}+e U
$$

where $G_{\mathrm{MH}^{*}}, G_{\mathrm{M}^{*}}$ and $G_{\mathrm{H}_{2}(\mathrm{~g})}$ represent the Gibbs free energies for the product, reactant and the gas phase $\mathrm{H}_{2}$, respectively, at room temperature, and $U$ is the potential relative to the RHE. To determine the energy barrier at $-0.6 \mathrm{~V}$ vs. RHE, we used the method proposed by Nie et al. ${ }^{45}$, as shown in the following expression

$$
E_{\text {act }}(U)=E_{\text {act }}^{0}\left(U^{0}\right)+\beta^{\prime}\left(U-U^{0}\right)
$$

where $E_{\text {act }}^{0}$ is the activation energy barrier determined by standard DFT approach, $U^{0}$ is the equilibrium potential, and it is calculated using Eq. (11) with respect to our system, by determining the potential at which the reaction free energy is zero (Supplementary Table 18). $U$ is the electrode potential relative to the RHE, and $\beta^{\prime}$ is the effective symmetry factor, which is assumed to be 0.5 for our system.

To estimate the charge transfer after adsorption, we use the Bader's approach as numerically applied by Henklemann's group ${ }^{46,47}$. To understand the charge redistribution after $\mathrm{C}_{2} \mathrm{H}_{2}$ adsorption on $\mathrm{Cu}$ surfaces, we plotted the charge density difference by subtracting the densities of $\mathrm{C}_{2} \mathrm{H}_{2}$ and $\mathrm{Cu}$ surface from the density of $\mathrm{C}_{2} \mathrm{H}_{2} / \mathrm{Cu}$ as expressed below

$$
\triangle \rho=\rho\left(\mathrm{C}_{2} \mathrm{H}_{2} / \mathrm{Cu}\right)-\rho\left(\mathrm{C}_{2} \mathrm{H}_{2}\right)-\rho(\mathrm{Cu})
$$

where $\rho\left(\mathrm{C}_{2} \mathrm{H}_{2} / \mathrm{Cu}\right), \rho\left(\mathrm{C}_{2} \mathrm{H}_{2}\right)$, and $\rho(\mathrm{Cu})$ are the charge densities of the $\mathrm{C}_{2} \mathrm{H}_{2} / \mathrm{Cu}$ system, and the corresponding parts of $\mathrm{C}_{2} \mathrm{H}_{2}$ and $\mathrm{Cu}$, respectively. By using the same atom positions as those in $\mathrm{C}_{2} \mathrm{H}_{2} / \mathrm{Cu}$, the charge densities of the latter two systems $\left(\mathrm{C}_{2} \mathrm{H}_{2}\right.$ and $\left.\mathrm{Cu}\right)$ were obtained.

\section{Data availability}

The data supporting the findings of this study are available within the article and its Supplementary Information. The optimized atomic positions of the reaction intermediates and transition states are available in the figshare repository (https:// doi.org/10.6084/m9.figshare.14184587). Source data are provided with this paper. Additional data are available from the corresponding authors on reasonable request.

Received: 27 July 2021; Accepted: 16 November 2021; Published online: 06 December 2021

\section{References}

1. Schobert, H. Production of acetylene and acetylene-based chemicals from coal. Chem. Rev. 114, 1743-1760 (2014).

2. Liu, C. J., Mallinson, R. \& Lobban, L. Nonoxidative methane conversion to acetylene over zeolite in a low temperature plasma. J. Catal. 179, 326-334 (1998).

3. Kang, H. S. et al. Methane to acetylene conversion by employing cost-effective low-temperature arc. Fuel. Process. Technol. 148, 209-216 (2016).

4. Abakumov, A. A. et al. Catalytic properties of reduced graphene oxide in acetylene hydrogenation. Carbon 157, 277-285 (2020).

5. Zhou, S., Kang, L., Xu, Z. \& Zhu, M. Catalytic performance and deactivation of $\mathrm{Ni} / \mathrm{MCM}-41$ catalyst in the hydrogenation of pure acetylene to ethylene. RSC Adv. 10, 1937-1945 (2020).

6. Feng, J. et al. Preparation and structure-property relationships of supported trimetallic PdAuAg catalysts for the selective hydrogenation of acetylene. J. Catal. 344, 854-864 (2016).

7. McCue, A. J., Guerrero-Ruiz, A., Rodríguez-Ramos, I. \& Anderson, J. A. Palladium sulphide-a highly selective catalyst for the gas phase hydrogenation of alkynes to alkenes. J. Catal. 340, 10-16 (2016).

8. Zhang, Q., Li, J., Liu, X. \& Zhu, Q. Synergetic effect of Pd and Ag dispersed on $\mathrm{Al}_{2} \mathrm{O}_{3}$ in the selective hydrogenation of acetylene. Appl. Catal. A 197, 221-228 (2000).

9. Huang, F. et al. Atomically dispersed Pd on nanodiamond/graphene hybrid for selective hydrogenation of acetylene. J. Am. Chem. Soc. 140, 13142-13146 (2018).

10. Kang, J. H., Shin, E. W., Kim, W. J., Park, J. D. \& Moon, S. H. Selective hydrogenation of acetylene on $\mathrm{TiO}_{2}$-added Pd catalysts. J. Catal. 208, 310-320 (2002).

11. Pei, G. X. et al. Ag alloyed Pd single-atom catalysts for efficient selective hydrogenation of acetylene to ethylene in excess ethylene. ACS Catal. $\mathbf{5}$ 3717-3725 (2015) 
12. Jia, J. F., Haraki, K., Kondo, J. N., Domen, K. \& Tamaru, K. Selective hydrogenation of acetylene over $\mathrm{Au} / \mathrm{Al}_{2} \mathrm{O}_{3}$ catalyst. J. Phys. Chem. B 104, 11153-11156 (2000).

13. Wu, Y. et al. Converting copper sulfide to copper with surface sulfur for electrocatalytic alkyne semi-hydrogenation with water. Nat. Commun. 12 3881 (2021).

14. Shi, R. et al. Room-temperature electrochemical acetylene reduction to ethylene with high conversion and selectivity. Nat. Catal. 4, 565-574 (2021).

15. Bu, J. et al. Selective electrocatalytic semihydrogenation of acetylene impurities for the production of polymer-grade ethylene. Nat. Catal. 4, 557-564 (2021).

16. Huang, B., Durante, C., Isse, A. A. \& Gennaro, A. Highly selective electrochemical hydrogenation of acetylene to ethylene at $\mathrm{Ag}$ and $\mathrm{Cu}$ cathodes. Electrochem. Commun. 34, 90-93 (2013).

17. Mark, H. B., Rubinson, J. F., Krotine, J., Vaughn, W. \& Goldschmidt, M. Catalysis of the reduction of acetylene at poly-3-methylthiophene electrodes. Electrochim. Acta 45, 4309-4313 (2000).

18. Rubinson, J. F., Behymer, T. D. \& Mark, H. B. Direct reduction of acetylene at molybdenum modified polymeric sulfur nitride, $(\mathrm{SN})_{\mathrm{x}}$, electrodes. J. Am. Chem. Soc. 104, 1224-1229 (1982).

19. Davitt, H. J. \& Albright, L. F. Electrochemical hydrogenation of ethylene, acetylene, and ethylene-acetylene mixtures. J. Electrochem. Soc. 118, 236-241 (1971).

20. Langer, S. H. \& Landi, H. P. The nature of electrogenerative hydrogenation. J. Am. Chem. Soc. 86, 4694-4698 (1964).

21. Ledwith, D. A. \& Schultz, F. A. Catalytic electrochemical reduction of acetylene in the presence of a molybdenum-cysteine complex. J. Am. Chem. Soc. 97, 6591-6593 (1975)

22. Shirakawa, H., Ito, T. \& Ikeda, S. Raman scattering and electronic spectra of poly(acetylene). Polym. J. 4, 460-462 (1973).

23. Bordiga, S., Groppo, E., Agostini, G., van Bokhoven, J. A. \& Lamberti, C. Reactivity of surface species in heterogeneous catalysts probed by in situ X-ray absorption techniques. Chem. Rev. 113, 1736-1850 (2013).

24. Liu, W., Lian, J. S. \& Jiang, Q. Theoretical study of $\mathrm{C}_{2} \mathrm{H}_{2}$ adsorbed on lowindex Cu surfaces. J. Phys. Chem. C 111, 18189-18194 (2007).

25. Fast, H. \& Welsh, H. L. High-resolution Raman spectra of acetylene, acetylene- $\mathrm{d}_{1}$, and acetylene- $\mathrm{d}_{2}$. J. Mol. Spectrosc. 41, 203-221 (1972).

26. Heinen, M., Jusys, Z. \& Behm, R. J. Ethanol, acetaldehyde and acetic acid adsorption/electrooxidation on a Pt thin film electrode under continuous electrolyte flow: an in situ ATR-FTIRS flow cell study. J. Phys. Chem. C 114, 9850-9864 (2010).

27. Wang, H., Zhou, Y. W. \& Cai, W. B. Recent applications of in situ ATR-IR spectroscopy in interfacial electrochemistry. Curr. Opin. Electrochem. 1, 73-79 (2017).

28. Futamata, M. In-situ ATR-IR study of water on gold electrode surface. Surf. Sci. 427-428, 179-183 (1999).

29. Berná, A., Kuzume, A., Herrero, E. \& Feliu, J. M. Ethylene adsorption and oxidation on $\mathrm{Pt}(\mathrm{h} \mathrm{k}$ l) in acidic media. Surf. Sci. 602, 84-94 (2008).

30. Andrews, J. R., Kettle, S. F. A., Powell, D. B. \& Sheppard, N. Infrared and Raman spectra of $\mathrm{HOs}_{3}\left(\mathrm{CH}=\mathrm{CH}_{2}\right)(\mathrm{CO})_{10}, \mathrm{H}_{2} \mathrm{Os}_{3}\left(\mathrm{C}=\mathrm{CH}_{2}\right)(\mathrm{CO})_{9}$, and $\mathrm{H}_{2} \mathrm{Os}_{3}(\mathrm{CO})_{10}$ : wavenumbers associated with olefinic and hydride ligands and the metal skeleton. Inorg. Chem. 21, 2874-2877 (1982).

31. Yu, L., Pan, X., Cao, X., Hu, P. \& Bao, X. Oxygen reduction reaction mechanism on nitrogen-doped graphene: a density functional theory study. J. Catal. 282, 183-190 (2011)

32. Baturina, O. A. et al. $\mathrm{CO}_{2}$ electroreduction to hydrocarbons on carbonsupported $\mathrm{Cu}$ nanoparticles. ACS Catal. 4, 3682-3695 (2014).

33. Moller, T. et al. Electrocatalytic $\mathrm{CO}_{2}$ reduction on $\mathrm{CuO}_{\mathrm{x}}$ nanocubes: tracking the evolution of chemical state, geometric structure, and catalytic selectivity using operando spectroscopy. Angew. Chem. Int. Ed. 59, 17974-17983 (2020).

34. Bewick, A., Jovićević, J. \& Thomas, B. Phase formation in the underpotential deposition of metals. Faraday Symp. Chem. Soc. 12, 24-35 (1977).

35. Kresse, G. \& Furthmuller, J. Efficiency of ab-initio total energy calculations for metals and semiconductors using a plane-wave basis set. Comp. Mater. Sci. 6, 15-50 (1996)

36. Kresse, G. \& Furthmuller, J. Efficient iterative schemes for ab initio totalenergy calculations using a plane-wave basis set. Phys. Rev. B 54, 11169-11186 (1996).

37. Perdew, J. P., Burke, K. \& Wang, Y. Generalized gradient approximation for the exchange-correlation hole of a many-electron system. Phys. Rev. B 54, 16533-16539 (1996).

38. Perdew, J. P., Burke, K. \& Ernzerhof, M. Generalized gradient approximation made simple. Phys. Rev. Lett. 77, 3865-3868 (1996).

39. Kresse, G. \& Joubert, D. From ultrasoft pseudopotentials to the projector augmented-wave method. Phys. Rev. B 59, 1758-1775 (1999).
40. Blochl, P. E. Projector augmented-wave method. Phys. Rev. B 50, 17953-17979 (1994).

41. Grimme, S., Antony, J., Ehrlich, S. \& Krieg, H. A consistent and accurate ab initio parametrization of density functional dispersion correction (DFT-D) for the 94 elements H-Pu. J. Chem. Phys. 132, 154104 (2010).

42. Grimme, S., Ehrlich, S. \& Goerigk, L. Effect of the damping function in dispersion corrected density functional theory. J. Comput. Chem. 32 1456-1465 (2011)

43. Hjorth Larsen, A. et al. The atomic simulation environment-a Python library for working with atoms. J. Phys. Condens. Matter 29, 273002 (2017).

44. Norskov, J. K. et al. Origin of the overpotential for oxygen reduction at a fuelcell cathode. J. Phys. Chem. B 108, 17886-17892 (2004).

45. Nie, X., Luo, W., Janik, M. J. \& Asthagiri, A. Reaction mechanisms of $\mathrm{CO}_{2}$ electrochemical reduction on $\mathrm{Cu}(111)$ determined with density functional theory. J. Catal. 312, 108-122 (2014).

46. Bader, R. F. W. Atom in Molecules a Quantum Theory. (Oxford University Press, New York, 1994).

47. Henkelman, G., Arnaldsson, A. \& Jonsson, H. A fast and robust algorithm for Bader decomposition of charge density. Comp. Mater. Sci. 36, 354-360 (2006).

\section{Acknowledgements}

We gratefully acknowledge the financial support from the National Natural Science Foundation of China (Nos. 21890753, 21988101, and 91845106), the Key Research Program of Frontier Sciences of the Chinese Academy of Sciences (No. QYZDB-SSWJSC020) and the DNL Cooperation Fund, CAS (No. DNL180201). We thank the staff at the BL14W1 beamline of the Shanghai Synchrotron Radiation Facilities for assistance with the EXAFS and XANES measurements. We appreciate the assistance of Prof. Bingwei Mao in the analysis of electrochemical data. K.U. acknowledges CAS-TWAS Presidents' Fellowship for financial support.

\section{Author contributions}

D.D. conceived the study. S.W. performed the materials synthesis, characterization, performance tests, and the in-situ tests. K.U. performed the DFT calculations. J.Y. and Z. Zhou performed the in-situ ATR-FTIR tests. Y.Z. and J.L. performed the in-situ Raman tests. J.H. assisted in the in-situ XANES tests. R.C. assisted in the material synthesis. R.C., Z. Zhang and J.H. assisted in products analysis. L.Y. supervised and assisted in the DFT calculations. Z.X. gave valuable advice on the research project. S.W., K.U., L.Y. and D.D. wrote the paper.

\section{Competing interests}

The authors declare no competing interests.

\section{Additional information}

Supplementary information The online version contains supplementary material available at https://doi.org/10.1038/s41467-021-27372-8.

Correspondence and requests for materials should be addressed to Liang Yu or Dehui Deng.

Peer review information Nature Communications thanks Alessandro Longo and the other, anonymous, reviewer(s) for their contribution to the peer review of this work.

Reprints and permission information is available at http://www.nature.com/reprints

Publisher's note Springer Nature remains neutral with regard to jurisdictional claims in published maps and institutional affiliations.

Open Access This article is licensed under a Creative Commons Attribution 4.0 International License, which permits use, sharing, adaptation, distribution and reproduction in any medium or format, as long as you give appropriate credit to the original author(s) and the source, provide a link to the Creative Commons license, and indicate if changes were made. The images or other third party material in this article are included in the article's Creative Commons license, unless indicated otherwise in a credit line to the material. If material is not included in the article's Creative Commons license and your intended use is not permitted by statutory regulation or exceeds the permitted use, you will need to obtain permission directly from the copyright holder. To view a copy of this license, visit http://creativecommons.org/ licenses/by/4.0/

(C) The Author(s) 2021 